\title{
Extracellular Vesicles: Packages Sent With Complement
}

\author{
Ebru Karasu' ${ }^{1}$, Steffen U. Eisenhardt ${ }^{2}$, Julia Harant ${ }^{1}$ and Markus Huber-Lang ${ }^{1 *}$ \\ ${ }^{1}$ Institute of Clinical and Experimental Trauma-Immunology, Universitätsklinikum Ulm, Ulm, Germany, ${ }^{2}$ Division of \\ Reconstructive Microsurgery, Department of Plastic and Hand Surgery, University of Freiburg Faculty of Medicine, \\ University of Freiburg Medical Centre, Freiburg, Germany
}

OPEN ACCESS

Edited by:

Uday Kishore,

Brunel University London,

United Kingdom

Reviewed by:

Michael Kirschfink,

Universität Heidelberg, Germany

Simon John Clark,

University of Manchester,

United Kingdom

*Correspondence:

Markus Huber-Lang

markus.huber-lang@uniklinik-ulm.de

Specialty section:

This article was submitted to Molecular Innate Immunity,

a section of the journal

Frontiers in Immunology

Received: 31 January 2018

Accepted: 23 March 2018

Published: 11 April 2018

Citation:

Karasu E, Eisenhardt SU, Harant J and Huber-Lang M (2018)

Extracellular Vesicles: Packages Sent With Complement.

Front. Immunol. 9:721. doi: 10.3389/fimmu.2018.00721
Cells communicate with other cells in their microenvironment by transferring lipids, peptides, RNA, and sugars in extracellular vesicles (EVs), thereby also influencing recipient cell functions. Several studies indicate that these vesicles are involved in a variety of critical cellular processes including immune, metabolic, and coagulatory responses and are thereby associated with several inflammatory diseases. Furthermore, EVs also possess anti-inflammatory properties and contribute to immune regulation, thus encouraging an emerging interest in investigating and clarifying mechanistic links between EVs and innate immunity. Current studies indicate complex interactions of the complement system with EVs, with a dramatic influence on local and systemic inflammation. During inflammatory conditions with highly activated complement, including after severe tissue trauma and during sepsis, elevated numbers of EVs were found in the circulation of patients. There is increasing evidence that these shed vesicles contain key complement factors as well as complement regulators on their surface, affecting inflammation and the course of disease. Taken together, interaction of EVs regulates complement activity and contributes to the pro- and anti-inflammatory immune balance. However, the molecular mechanisms behind this interaction remain elusive and require further investigation. The aim of this review is to summarize the limited current knowledge on the crosstalk between complement and EVs. A further aspect is the clinical relevance of EVs with an emphasis on their capacity as potential therapeutic vehicles in the field of translational medicine.

Keywords: extracellular vesicles, exosomes, microvesicles, complement, complement activation, immune response, therapeutic vehicle

\section{BACKGROUND}

Extracellular vesicles (EVs) are likely to represent an efficient, robust, and economic manner for exchanging information between cells. Throughout evolution, communication via extracellular cargo carriers appears to be a highly conserved method. This form of cell-to-cell communication is found in lower eukaryotes, bacteria, and plants as well as in higher organisms (1). In addition

Abbreviations: ALS, amyotrophic lateral sclerosis; AMD, age-related macular degeneration; AP, alternative pathway; APC, antigen-presenting cell; BBB, blood-brain-barrier; CARPA, complement activation related pseudoallergy; CCR5, C-C chemokine receptor type 5; CME, clathrin-mediated endocytosis; CNS, central nervous system; CP, classical pathway; CR1, complement receptor 1; CRP, C-reactive protein; DC, dendritic cell; EGFRvIII, epidermal growth factor receptor variant III; EV, extracellular vesicle; fMLP, N-formyl-methionyl-leucyl-phenylalanine; GPI, glycosylphosphatidylinositol; MAC, membrane attack complex; MARCKS, myristoylated alanine-rich C-kinase substrate; $\mathrm{mCRP}$, monomeric CRP also neoepitope expressing CRP; MHC, major histocompatibility complex; MMP-2/-9, matrix metalloproteinase-2/-9; MV, microvesicle; MVB, multivesicular bodies; pCRP, native/pentameric CRP; pCRP*, neoepitope expressing CRP; PEG, polyethyleneglycol; PMN, polymorphonuclear leukocyte; PS, Phosphatidylserine; RPE, retinal pigmented epithelium; SNARE, soluble N-ethylmaleimide-sensitive fusion factor attachment protein receptor; TBI, traumatic brain injury; TF, Tissue factor. 
to cellular communication, EVs are important for survival and adaption to (micro-) environmental changes. For example, bacteria are able to form EVs, termed bacterial outer membrane vesicles (OMV), which contain RNA, DNA, endotoxins, or virulent molecules $(2,3)$. By shedding OMV with specific cargoes, bacteria influence the behavior and/or property of other bacteria (3). These vesicles play a crucial role in quorum sensing, a known strategy in bacterial colonies to adapt their social group activity to their environment by sending extracellular "packages" (4). Plants are also known to produce EVs, particularly in response to pathogen exposure (5). However, the role of EVs in mammals appears to be more complex. Depending on their content, these packages are capable of influencing a variety of cellular functions and contribute to physiological homeostasis, but also have profound roles in pathological conditions, as illustrated in Figure 1. For example, shedding of endothelial cell-derived vesicles with matrix metalloproteases (MMPs) has been described, which is important for matrix degradation and angiogenesis during wound healing and development, but also during tumor progression (6). Their association with tumors has been extensively investigated. Early studies revealed the involvement of EVs in tumor malignancy by transferring metastatic capacity to other cancer cells (7). Addressing immunity, recent findings suggested that EVs have profound effects on the innate immune system, and consequently are also able to modulate adaptive immunity (8). In particular, the complement system as the first-line of innate immunity represents an important interaction partner for EVs and together they are associated with thrombotic and inflammatory conditions and appear to influence patient morbidity and mortality (9-11). This review focuses on the current state of knowledge on interactions between EVs and complement.

\section{EXTRACELLULAR VESICLES}

\section{Morphological Characterization}

During programmed cell death, cells are known to release vesicles to the extracellular environment (12). However, the fact that healthy cells also release vesicles to the extracellular environment has only been recently discovered. These cell-derived particles, termed EVs, can be assigned to three main groups: apoptotic bodies, exosomes, and microvesicles (MVs). This classification is based on their characteristic features, including cellular origin and their size, function, composition, and molecular cargo (1).

Apoptotic bodies are released solely from cells undergoing apoptosis $(12,13)$. Cellular fragmentation occurs with the formation of 1,000-5,000 nm apoptotic blebs, which become packed with intact cellular organelles, DNA, and histones, and subsequently being phagocytized by neighboring live cells without activating an inflammatory or autoimmune response (13-15). By contrast, both exosomes and MVs are released from healthy cells during physiological and pathological conditions.

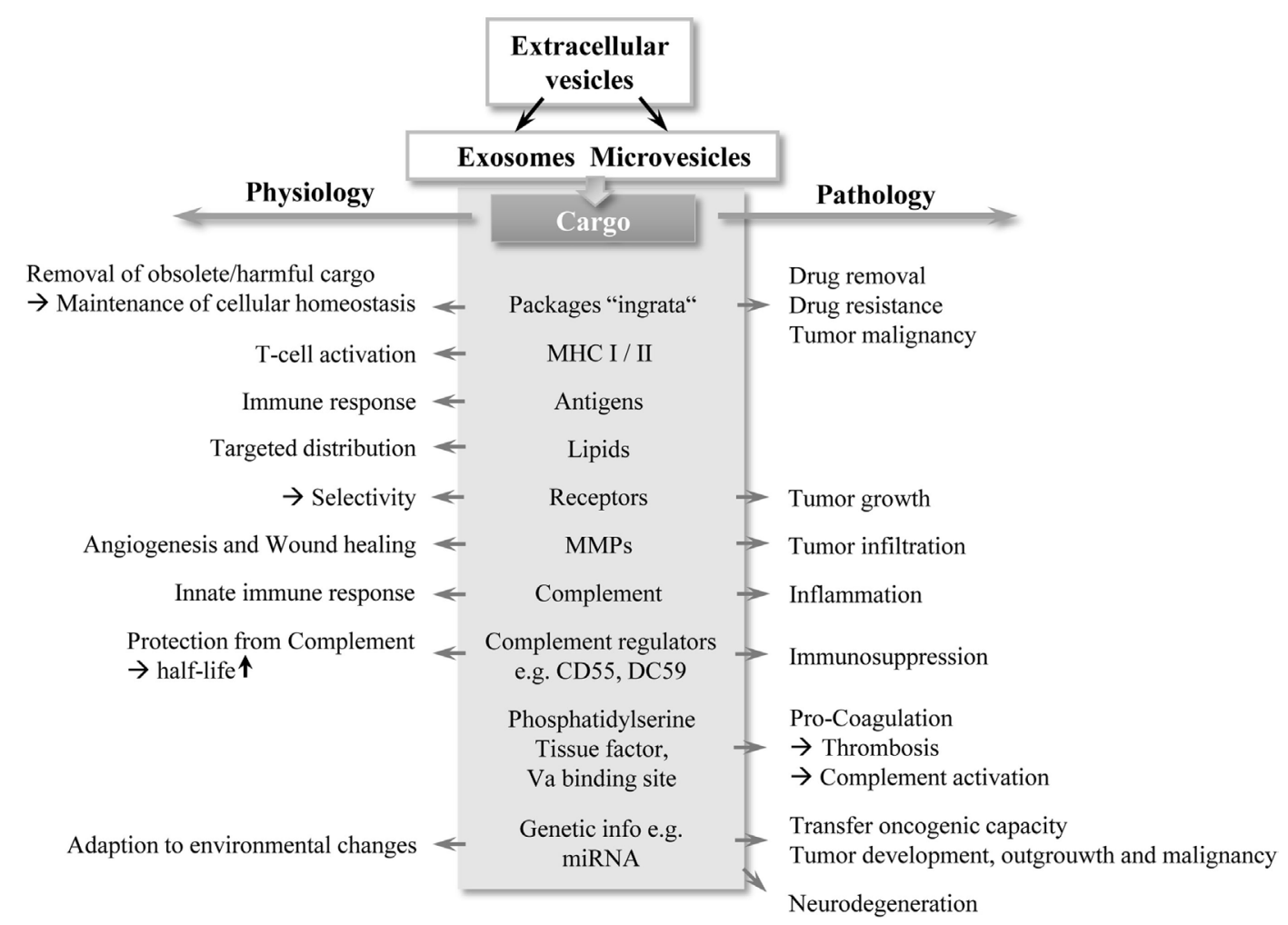

FIGURE 1 | A double-edged sword: schematic overview of EV functions. EVs, in particular exosomes and MVs contain different cargo types, highlighted in gray in the middle section in the figure. Depending on their cargo composition, EVs exert bi-directed functions (depicted by arrows) with important contribution to physiology and pathology. Abbreviations: EV, extracellular vesicles; MHC: major histocompatibility complex; MMP: matrix metalloproteinase; MV, microvesicle. 
Exosomes are small spherical vesicles of size $30-120 \mathrm{~nm}$ and are produced from late endocytic compartments, known as multivesicular bodies (MVBs) (14). They are produced by inward invagination of endosomal membranes to form MVBs, which subsequently fuse with the plasma membrane and release their intraluminal vesicles as exosomes to the extracellular milieu (16). Because of their endocytic origin, exosomes are commonly enriched in endosome-associated proteins, including Rab GTPases, SNAREs, annexins, and tetraspanins (CD9, CD63, and CD81). Some of these proteins (e.g., the endosome-specific proteins Alix and Tsg101) are normally used as exosome markers $(17,18)$. However, recent studies identified that exosome-specific markers are also present in MVs (19).

Microvesicles, also referred as ectosomes, microparticles and nanoparticles, directly derive from the cell surface and are larger than exosomes, with a size ranging from 100 to $1,000 \mathrm{~nm}(20)$. MVs expose high levels of integrins (21). Although common protein markers used to define these vesicles are selectins, integrins, and the CD40 ligand, less is known about the protein content of MVs (22).

A major and still ongoing challenge is to define methods that will allow discrimination between exosomes and MVs $(23,24)$. At present, a precise definition and terminology for the characterization of exosomes and MVs remain to be resolved (25). It appears to be difficult to distinguish between these two subgroups when based on characteristics like structure, size, cargo, and protein composition (26). Therefore, there is a broad interest in novel methods of isolation and purification. To further understand the origin of the different vesicle populations and to unravel their (patho-) physiological and pathological relevance, a better mechanistic understanding on their biogenesis and secretion is also required (24).

\section{Multiple Functions of EVs Cellular Homeostasis}

Several studies have demonstrated that eukaryotic vesicles are used to remove obsolete, undesired, or even dangerous cellular molecules or protect the cells and organism from waste or drug, thus contributing to maintenance of cellular homeostasis $(1,26)$. Interestingly, aged erythrocytes release hemoglobin-containing EVs to enhance clearance of old erythrocytes from the circulation (27). Furthermore, cells are able to remove harmful cytoplasmic DNA in exosomes to maintain cellular homeostasis (28).

\section{Transfer of Genetic Information}

Recent studies indicated that EVs can contain genetic material such as RNA and noncoding RNAs, including miRNA, and are indispensable for cellular communication and mRNA homeostasis (29). Further studies demonstrated that such EV cargoes could be successfully transferred to recipient cells in culture, leading to functional consequences for the recipient cell $(30,31)$. Specific miRNAs are enriched in EVs derived from immune cells and thereby mediate proper immune responses or represent important regulators during inflammation $(1,22)$. However, tumor-derived EVs containing specific miRNAs play profound roles in tumor progression, for example, by supporting immunosuppression or transferring oncogenic capacity $(7,22,32)$.

\section{Promotion of Coagulation}

Although vesicle release has been proposed to be beneficial for the cell, the vesicles can also represent a danger to their environment, for example in blood, where vesicles can provide a surface as a focal point for coagulation activation, resulting finally in thrombus formation (33). Blood coagulation is also triggered by vesicle-mediated interaction between macrophages, neutrophils, and thrombocytes. Thrombocytes shed MVs bearing tissue factor (TF) on their surface, which interact with macrophages, endothelial cells, or further thrombocytes $(20,34)$. Supporting this, MV-bound TF can be detected in a variety of diseases, including trauma, sepsis, and cancer $(35,36)$. This so-called "blood-borne" TF may contribute to the development of thrombosis that is associated with these diseases (36-39).

\section{Immune Modulation}

A sufficient immune response is characterized by a sufficient communication between the innate and the adaptive immune system (40). Immune cell populations from both the innate and adaptive immune systems shed EVs with specific cargo, thus an exchange of EVs appears to be crucially involved in regulation of the immune responses (41). Exosomes released by immune cells have a bi-directional function; they may act as antigenpresenting vesicles, thereby for example stimulating anti-tumoral immune responses, or as inducers of tolerogenic effects suppressing inflammation $(8,42,43)$. Early studies showed that immune cell-derived EVs carry MHC class I, MHC class II, and T cell co-stimulatory molecules $(43,44)$. In vitro as well as animal studies demonstrated that antigen-presenting cell (APC)-derived exosomes effectively stimulate $\mathrm{T}$-cell responses, thus they are critical for proper immunological responses (45). Macrophages/ monocytes are known to release EVs enriched with the miRNA molecule miR-223, a key regulator of myeloid cell proliferation and differentiation (46). Polymorphonuclear leukocyte (PMN)derived MVs specifically bind to macrophages/monocytes, dendritic cells (DCs), and endothelial cells and thereby can alter the immune response. Interestingly, immature DCs alter their immunological function in the presence of PMN-derived MVs and consequently feature tolerogenic properties (1).

\section{Specificity and Stability}

In the human body, EVs can be released from many, if not all, cell types and are abundant in many body fluids, including blood, urine, saliva, cerebrospinal fluid (CSF), ascites, and breast milk (47-55). In this context, it remains unclear, whether shed EVs are addressed for a specific recipient cell, and if so, what causes tissue or organ specificity, their stability and their uptake. Proteomic profiling of EVs identified different types of glycan-binding proteins or glycosylation patterns, which appear to determine the target cells or influence interactions with them (1). For example, B-cell-derived EVs contain $\alpha$-2,3-linked sialic acid, which can be captured by sialoadhesin (CD169), an adhesion molecule found on macrophage surfaces (56). Because of their variable protein content and composition, EV s have different forms of functionality. Surface-expressed receptors appear to play an essential role in bio-distribution, or binding of EVs to their target cells or to extracellular matrix components (1). Of note, by transferring 
functionally active receptors, including CCR5, the target-cell phenotype can be modified or even intracellular signaling pathways can be influenced (57). Once released, EVs can bind to neighboring cells or to the extracellular matrix components, or traffic passively through the bloodstream or body fluids (8). The bio-distribution of EVs depends on several aspects, including the parent cell source, availability of recipient cell types, and clearance from the circulation by retention, uptake, and internalization (1). Certain blood-borne EVs are rapidly captured by marginal zone phagocytes of the spleen, liver Kupffer cells, and DCs and macrophages in the lung, resulting in a short half-life in the circulation $(44,58)$. However, human platelet-derived EVs display a half-life of up to $6 \mathrm{~h}$ (59). Furthermore, some EV s express glycosylphosphatidylinositol (GPI)-anchored CD55 and CD59, thereby protecting them from complement-mediated lysis (60). EVs display different lipid compositions of the membrane bilayer in comparison to their parent cells, suggesting a sorting process during EV formation (48). Many studies confirmed a specific lipid sorting, with a predominant content of cholesterol, phosphatidylserine (PS) and sphingolipids present in EVs. Cholesterol appears to be an essential lipid for regulating EV formation and release $(38,61)$. It has been proposed that EVs enriched with cholesterol and long saturated fatty acids of sphingolipids display a tighter lipid packaging and improved physiochemical features by providing greater stability, structural rigidity, and resistance (1). Established uptake mechanisms include clathrin-mediated endocytosis (CME), phagocytosis, macropinocytosis, and plasma or endosomal membrane fusion, which are reviewed elsewhere (62). Noteworthy, $\mathrm{pH}$ appears to modulate uptake capacity by influencing electrostatic charges between EVs and the cell plasma membrane (63).

\section{EV-COMPLEMENT SYSTEM INTERACTION}

\section{The Complement System}

The complement system represents an important arm of innate immunity and is frequently referred to as the first barrier against pathogens (64). It is well known that the complement cascade consists of more than 30 proteins, which function in a wellorchestrated order of activation and regulation (65). Beyond opsonization and pathogen elimination, this biological system is involved in the regulation of the cytokine/chemokine release, stays in close interaction with the coagulation cascade, and has a crucial impact in tissue inflammation and repair (66). Generally, three pathways for complement activation have been described: the classical pathway (CP), the lectin pathway, and the alternative pathway. All three pathways lead to the generation of a $\mathrm{C} 3$ convertase which subsequently cleaves the central molecule C3 and leads to the release of anaphylatoxins C3a and C5a, and activation of the terminal cascade of complement, resulting in the membrane attack complex (MAC) formation with cell lysis (67). The anaphylatoxins can also bind to their respective receptors (C3aR, C5aR1, C5aR2), and mainly exert inflammatory effects, including leukocyte attraction $(65,68)$. Recently, the serine protease thrombins have been identified to activate the complement system by direct cleavage of C3 and C5 (65). A simplified overview of the complement system is presented in Figure 2.

\section{EVs and Complement As Interaction Partners}

Higher numbers of circulating vesicles are found in local and systemic inflammation, which is also characterized by the appearance of complement activation products $(10,36)$. Their co-presence suggests a link between the complement system and EVs, which may influence innate as well as adaptive immune responses. To date, literature in this research field is limited and warrants further experimental investigation. Nevertheless, several studies provide increasing evidence supporting an important crosstalk between these biological systems. On the cellular level, endothelial cells, PMNs, monocytes, erythrocytes, and platelets appear to be mainly involved $(9,11,42,69)$. For both systems, it has been shown that activation and interaction of the complement system with other cascades such as coagulation and MVs lead to both pro-inflammatory and anti-inflammatory directions and can also affect morbidity and mortality in diseases, including the setting of trauma and sepsis $(10,36)$.

\section{Complement Evasion Through EV Shedding}

The first description of vesicle-complement interaction focused on the release of vesicles directly from the cell membrane (ectocytosis) upon stimulation of neutrophils with sublytic amounts of the MAC (70). After complement attack, a large number of membrane protrusions appear on the cellular surface following vesicle shedding from the cells $(10,71)$. In accordance with this, PMNs activated with either $\mathrm{N}$-formyl-methionyl-leucyl-phenylalanine (fMLP) or C5a release vesicles from their membrane within minutes, which overall exhibit features corresponding to MVs (72).

Strikingly, various cells are able to evade complement attack by allowing the removal of the MAC from the cell surface by a calcium-dependent elimination process (73-75). Several studies demonstrated that MAC clearance occurred actively and rapidly from the plasma membrane, assuring cell survival and recovery from complement attack. Such complement-induced MV shedding was reported in erythrocytes, PMNs, glomerular epithelial cells, and tumor cell lines, including U937 and K562 $(73,74,76,77)$.

Moreover, cytotoxic effects were found on oligodendrocytes after complement activation with resultant C9 formation, which in turn release MAC-enriched vesicles from their surface $(78,79)$. In support of this, identical MAC-containing vesicles were detected in the CSF of multiple sclerosis patients, indicating that complement-mediated injury contributes to myelin damage in vivo, where vesicle shedding appears as an important regulatory process (79).

\section{EVs Modulate Immune Responses via Interaction With Complement Regulators}

In addition to protection from complement attack, EVs are key players in the regulation of immunological responses. APCs interact with immune cells, particularly T-cells, by shedding exosomes with T-cell stimulatory properties (8). However, exosomes, derived 


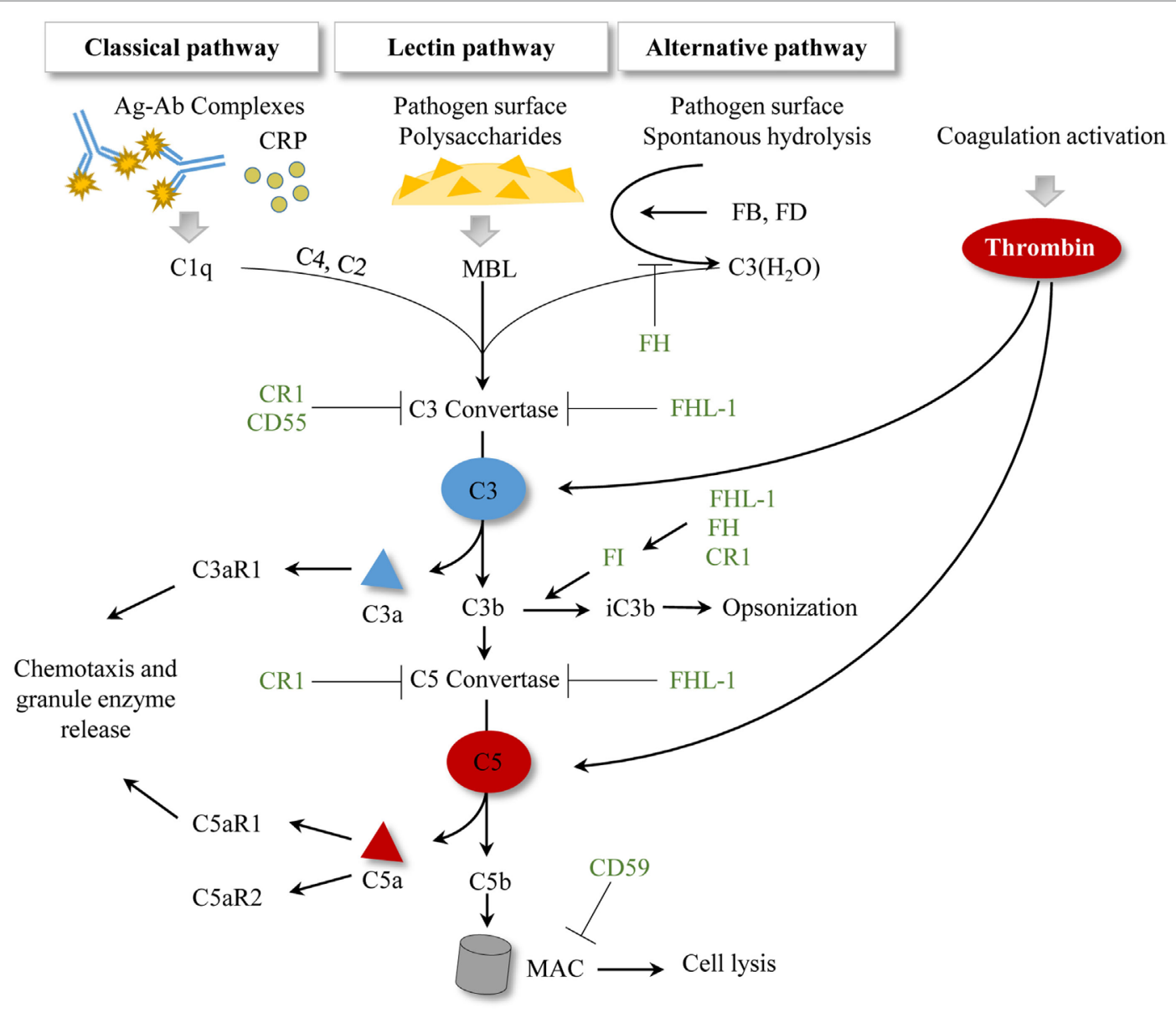

FIGURE 2 | Simplified scheme of established complement activation pathways. To date, three activation pathways for complement have been described. Antibody-antigen complexes or the acute phase protein CRP initiate the classical pathway by allowing C1q binding. The lectin pathway is initiated by MBL binding to pathogen surfaces and to pathogen-specific proteins. The alternative pathway is characterized by spontaneous hydrolysis of $\mathrm{C} 3$ to $\mathrm{C} 3\left(\mathrm{H}_{2} \mathrm{O}\right)$, which can in turn bind the plasma proteins FB and FD. All three pathways result in a C3 convertase, which cleaves C3 and subsequently generates C5 convertases and initiates MAC formation. Activation of the coagulation cascade generates thrombin, which can cleave C3 and C5 in a C3-/C5-convertase independent manner. Complement regulatory proteins are represented in green. CR1 facilitates the decay of C3 and C5 convertases and is a cofactor of Fl. CD55 accelerates the decay of the C3 convertase. CD59 inhibits the MAC formation. Factor I regulates the processing of C3b to iC3b, where FHL-1, FH, and CR1 show cofactor activities. FH also regulates the formation of the alternative pathway C3 convertase. FHL-1 supports the decay of C3 and C5 convertases. Abbreviations: Ag-Ab, antigen-antibody; CR1, complement receptor 1; CRP, c-reactive protein; FB, factor B; FD, factor D; FH, factor H; FHL-1, factor H-like protein 1; Fl, factor I; MAC, membrane attack complex; MBL, mannan-binding lectin.

from antigen-processing compartments, are likely to be associated with antigenic proteins, and thereby are particularly prone to bind immunoglobulins $(60,80)$. These in turn activate the classical pathway (CP) resulting in rapid opsonization and lysis. Remarkably, even non-antigen harboring exosomes are described to activate the complement cascade, where C1q plays an important role by simply binding to lipid membranes through electrostatic interactions rather than in an antibody-dependent manner (81, 82). However, exosomes derived from APCs also appear capable of escaping from complement-mediated lysis. Interestingly, these exosomes express the GPI-anchored complement regulators CD55 and CD59 (60). CD55 regulates the C3 and C5 convertases, whereas CD59 inhibits the formation of MAC (83). These findings strongly indicate that exosomes equipped with complement regulators like CD55 and CD59 are able to escape complement attack, which contributes to their stability and longer circulatory availability (84). These vesicle-bound complement regulators may be important for regulation of the immune response by stimulating/inhibiting T-cell responses as well as cross-priming with other immune cells (60).

A further member of the complement regulators, complement receptor 1 (CR1) also interacts with EVs. PMN-derived MVs are described to express clusters of CR1, which allow them to bind efficiently to opsonized bacteria. Interestingly, of the other complement regulatory proteins expressed by the PMN, only CD59 co-localized with CR1, whereas CD55 was almost absent (72). Of note, in the absence of complement molecules, PMN-derived MVs preferentially bind to endothelial cells, whereas in the presence of complement, adhesive features of PMN-derived MVs change: $\mathrm{PMN}$-derived MVs can bind C1q, and subsequently C3, and are 
thereby capable of binding to erythrocytes via CR1 (85). By binding to erythrocytes, these opsonized MVs may resemble circulating immune complexes, which are transported to the liver and spleen and are cleared rapidly from the circulation. Consequently, their adherence to erythrocytes may prevent binding to endothelial cells, thus leading to reduced bio-availability for interactions with other immune cells and avoiding harmful fixation in tissues $(86,87)$. Although speculative, binding of MVs to erythrocytes may also result in altered erythrocyte function. Aged erythrocytes shed MVs enriched with CR1 and CD59 (88). Therefore, old erythrocytes may no longer be protected from opsonization and complement attack, which enhances their removal from the circulation by phagocytosis. Overall, the release of cellular complement regulators via MVs appears to be important during physiological but also pathological conditions. The presence of complement regulators on EVs was also described in the context of age-related macular degeneration (AMD). AMD is characterized by a complement-mediated inflammation in the macula leading to cellular damage and vision loss. Retinal pigmented epithelium (RPE) cells possess immunosuppressive features and modulate monocyte activity through EVs. Furthermore, RPEderived EVs appear to regulate complement activity by interacting with complement regulators. Under inflammatory conditions, membrane complement regulators including CD55, CD59 and CD46 are present on RPE-derived EVs. As a consequence, cells are vulnerable to a complement attack, which can lead to cellular death (89). Additionally, mutations in complement regulator genes, including the CFH gene encoding for FH and FHL-1 are involved in the pathology of AMD (90-92). Besides C3 binding, $\mathrm{RPE}$-derived EVs are able to bind $\mathrm{FH}$, suggesting a regulatory function (93). Mutations in the CFH gene may impair the binding of FH and FHL-1 to EVs. Theoretically, in the absence of FH/ FHL-1, C3-coated EVs may be recognized as immunological complexes by invading immune cells, and thus may support the inflammatory process in AMD.

\section{EV-Mediated Immunosuppression via C5aR1 Shedding}

Frequently, immunosuppression is a consequence of multiple trauma, hemorrhagic shock, or progressive sepsis, leading to impaired immune function by development of complementopathy and coagulopathy with a fatal clinical outcome (94-96). Rapid complement activation and exhaustion after severe tissue trauma lead to complement dysregulation (94). In clinical sepsis, an enhanced presence of the complement C5a receptor C5aR1 on MVs in patients with septic shock has been demonstrated, suggesting an important role in the outcome. In addition, MV shedding with C5aR1 negatively correlated with survival in sepsis patients (10). In a cohort of sepsis patients, neutrophils exhibit decreased C5aR1 expression, but enhanced numbers of circulating C5aR1 (C5aR1 on MVs), resulting in an impairment of neutrophil function. Sera from non-survivors after septic shock contained much more circulating $\mathrm{C} 5 \mathrm{aR} 1$ than in sera from survivors. However, it cannot be excluded that the circulating C5aR1 was also bound to membrane fragments other than MVs. Nevertheless, in vitro experiments with human neutrophils demonstrated that treatment with $\mathrm{C} 5 \mathrm{a}$ or the acute phase-protein C-reactive-protein
(CRP) - both of which are significantly enhanced in plasma during septic shock-resulted in an almost complete loss of C5aR1 on neutrophils, and significantly increased numbers of MVs carrying C5aR1 on their surface leading to an acquired dysfunction of neutrophils (10). Furthermore, in a rodent sepsis model, circulating C5aR1 was co-expressed with a granulocyte-specific MV marker CD66e, confirming microvesicle-mediated shedding of C5aR1 (10). In support of this, a further study identified a 20 -fold higher gene expression of C5aR1 in blood leukocytes of 26 patients with severe sepsis compared to healthy volunteers (97). This finding may be explained by a cellular compensatory mechanism, by upregulating de novo synthesis of C5aR1 due to enhanced C5aR1 shedding on microvesicles.

\section{EVs As a Platform for Complement Activation}

In addition to regulatory functions, EV interactions with complement may aggravate the complement response. Several studies revealed increased numbers of circulating MVs in both thrombotic and inflammatory diseases, where complement activation is also present (98). In synovial fluid of rheumatoid arthritis patients, significantly increased levels of leukocyte-derived MVs were detected with complement components bound on their surface, including C1q, C4, and C3 (11). In vitro studies provided further evidence by demonstrating that leukocytederived MVs can bind $\mathrm{C} 1 \mathrm{q}$ and activate the $\mathrm{CP}$, subsequently leading to deposition of C4 and C3 $(70,75,76)$. In accordance, Gasser and Schifferli demonstrated that PMN-derived MVs could activate complement. This activation was mediated by the $\mathrm{CP}$, and only after C1q deposition on MVs, C4 and C3 fragment fixation did occur (85). Further downstream, activation of MAC formation occurred on the surface of MVs (70). In agreement with this, human erythrocyte-derived MVs were reported to fix C1q, which was followed by activation of the CP with binding of C3 fragments (99). As mentioned above, elevated numbers of circulating EVs (particularly MVs) are present during inflammatory conditions, which are generally associated with enhanced complement activation (100). In conclusion, cells may primarily compensate overwhelming complement activation by releasing more MVs. These MVs may act as scavengers by fixing complement molecules and allowing MAC formation on the MV surfaces, thereby protecting the parent cells and tissues from complement attack.

C-reactive protein (CRP) was also described as an important mediator for complement binding on MV surfaces. CRP is synthesized in the liver in a complement-dependent manner in its native pentameric form (pCRP) (101). According to the current findings, pCRP localizes to injured tissues and undergoes conformational changes, leading to the formation of pCRP*, which still maintains the symmetry of pCRP, but is detected by a neoepitope-specific antibody, and/or can even dissociate into neoepitope-expressing monomeric CRP (mCRP) (102). Studies indicate that both $\mathrm{pCRP}^{\star}$ and $\mathrm{mCRP}$ aggravate the inflammatory response by complement activation, but currently, it is impossible to distinguish between $\mathrm{pCRP}^{\star}$ and mCRP (102-104). Interestingly, it was also demonstrated that binding pCRP on $\mathrm{MV}$ surfaces induced the generation of $\mathrm{pCRP}^{*} / \mathrm{mCRP}$, which in turn can activate the complement system (102). The authors 
demonstrated that MVs with bound CRP could fix C1q, thus activating the CP. This study could detect significantly higher levels of CRP bound on MVs in patients after myocardial infarction compared to healthy controls. Additionally, Braig et al. analyzed the presence of native CRP (pCRP) and neo-epitope-expressing $\mathrm{CRP}\left(\mathrm{pCRP}{ }^{\star} / \mathrm{mCRP}\right.$ ) on MVs of different cellular origins (leukocytes, platelets, and activated platelets), which confirmed findings of Habersberger et al. and suggests a diagnostic use in this clinical setting $(102,105)$. In all cellular populations, a significantly higher deposition of both $\mathrm{pCRP}$ and $\mathrm{pCRP}{ }^{\star} / \mathrm{mCRP}$ was detectable on the respective MVs (102). In vitro studies revealed a significantly elevated deposition of the $\mathrm{C} 3$ cleavage product $\mathrm{C} 3 \mathrm{~b}$ and $\mathrm{iC} 3 \mathrm{~b}$ on $\mathrm{MVs}$ in the presence of $\mathrm{pCRP}^{\star}$, suggesting a much more complex interaction mechanism with the AP. In contrast to $\mathrm{C} 3 \mathrm{~b}, \mathrm{iC} 3 \mathrm{~b}$ is not able to form an AP C3 convertase and thus functions rather anti-inflammatory or tolerogenic (106-108). Furthermore, surface bound $\mathrm{iC} 3 \mathrm{~b}$ is a potent oposonin, interacts with receptors, and stimulates phagocytosis and antigen presentation to cells of the adaptive immune system (109). Factor I and the cofactors FH, FHL-1, and CR1 are known to process C3b into its inactive form iC3b (Figure 2). So far, the mechanisms behind the observed $\mathrm{C} 3 \mathrm{~b}$ and $\mathrm{iC} 3 \mathrm{~b}$ presence on MVs remain elusive. Furthermore, it is not clear how CRP is involved in this process. On the one hand, the presence of $\mathrm{pCRP}^{\star}$ on MVs may enhance the extent of complement activity by recruiting factor $\mathrm{B}$ and factor $\mathrm{D}$, resulting in $\mathrm{C} 3 \mathrm{~b}$ formation. On the other hand, MVs bound with $\mathrm{pCRP}^{*} / \mathrm{mCRP}$ may recruit FI, FH, and/or FHL-1, which in turn processes the bound or circulating $\mathrm{C} 3 \mathrm{~b}$ to $\mathrm{iC} 3 \mathrm{~b}$. Interestingly, a current study revealed that the complement regulator FHL-1 is able to bind pCRP as well as mCRP, and FH is able to bind mCRP (110). Since pCRP* also expresses a neoepitope, it can be speculated, that $\mathrm{pCRP} / \mathrm{pCRP}{ }^{\star}$ and/or mCRP, which are bound on MVs support FH and FHL-1 recruitment, which in turn enhances the processing of $\mathrm{C} 3 \mathrm{~b}$ to $\mathrm{iC} 3 \mathrm{~b}$. However, even in the absence of CRP, C3 and $\mathrm{iC} 3 \mathrm{~b}$ are bound on MVs, assuming a further and CRP-independent mechanism $(102,111)$. It may be possible that C3-coated MVs resemble opsonized pathogen surfaces, resulting in recruitment of FB and FD and in forming an AP C3 convertase. Another explanation include that hydrolyzed $\mathrm{C} 3, \mathrm{C} 3\left(\mathrm{H}_{2} \mathrm{O}\right)$, is generated and/or bound on MV surfaces, where it may also form an AP C3 convertase. The formed AP C3 convertase may cleave other circulating $\mathrm{C} 3$ into $\mathrm{C} 3 \mathrm{~b}$ and causes its deposition on MVs. Subsequently, EVs may recruit or bind FH, FHL-1, and FI to process $\mathrm{C} 3 \mathrm{~b}$ to $\mathrm{iC} 3 \mathrm{~b}$. However, it is still probable that $\mathrm{C} 3 \mathrm{~b}$ and iC3b may be generated through the AP without MV involvement, thus MVs only provide a surface for the cleaved products $\mathrm{C} 3 \mathrm{~b}$ and iC3b. Therefore, further investigations are necessary to clarify the presence of C3, C3b, and iC3b on MVs.

\section{EV-Interaction With the Coagulation System Activates Complement}

Blood coagulation is known to exhibit extensive crosstalk with the complement system. In particular, activation complement system includes the involvement of the coagulation molecule and serine protease thrombin, which is able to directly cleave both C3 and C5 (Figure 2). Independent of their cellular origin, MVs harbor PS on their surface. In vitro studies revealed that these vesicles have pro-coagulant properties and PS represents a platform for thrombin generation thereby also activating complement (112). Furthermore, erythrocyte-derived MVs are described to activate complement via a thrombin-dependent mechanism (69).

Additionally, endothelial cell-derived MVs appear to play an important role in coagulation-mediated complement activation. It is known that endothelial cells express complement factors and regulators as well as receptors on their surface (113). Particularly during infectious or inflammatory conditions, endothelial cells revealed a deposition of complement molecules on their surface (114). Consequently, the endothelium is able to mediate MV shedding after complement activation (9). MAC formation on endothelial cells was reported to be followed by the shedding of MVs with MAC on their surface and of note, additionally expressing binding sites for the clotting factor Va and thus support prothrombinase activity (115). The prothrombinase complex includes $\mathrm{Va}, \mathrm{Xa}$, and prothrombin; activation of the complex can lead to thrombin formation, which mediates clotting as well as complement activation $(116,117)$. Furthermore, blood coagulation can be activated by the release of TF-coated MVs (20). TF is a known key molecule for coagulation and thrombosis initiation (118). TF-coated vesicles have been described to interact with macrophages, endothelial cells, and thrombocytes (20). Therefore, it can be speculated that in addition to blood coagulation, TF-coated MVs are able to initiate complement activation. Although TF alone is unable to directly interact with C3 or C5, formation of thrombin is triggered when membrane-localized TF is exposed to blood $(119,120)$. These blood-borne TF-MVs may be involved in thrombin formation (38). In this context, thrombin as a potent serine protease can directly cleave C3 and C5 (117).

Taken together, current studies provide evidence that complement can promote EV shedding and activation and vice versa. Their crosstalk appears to exert crucial effects on regulating the extent of complement activity and thus modulating both the innate and adaptive immune responses (Figure 3).

\section{CLINICAL RELEVANCE}

\section{EVs in Diseases Oncologic Diseases}

Early studies indicate a strong contribution of EVs in tumor outgrowth and progression (7). One major known mechanism of $\mathrm{EV}$ contribution in this process is mediated by transferring oncogenic activity to other cancer cells. Glioma cells expressing epidermal growth factor receptor variant III (EGFRvIII) secrete MVs harboring EGFRvIII and transfer this receptor to EGFRvIIInegative cancer cells within the same primary tumor, resulting in tumor growth (121). Furthermore, $\mathrm{pH}$ is an important factor for EV uptake into recipient cells (63). An increased fusion efficiency of tumor-derived exosomes was identified in cells of metastatic origin in comparison to those derived from primary tumors or normal cells (63). Strikingly, the responsible mechanism for enhanced fusion efficacy was mediated by an acid $\mathrm{pH}$ in the tumor microenvironment, which influences rigidity, fluidity, and lipid composition resulting in direct plasma membrane fusion of EVs with enhanced EV trafficking between tumor cells (63). In 


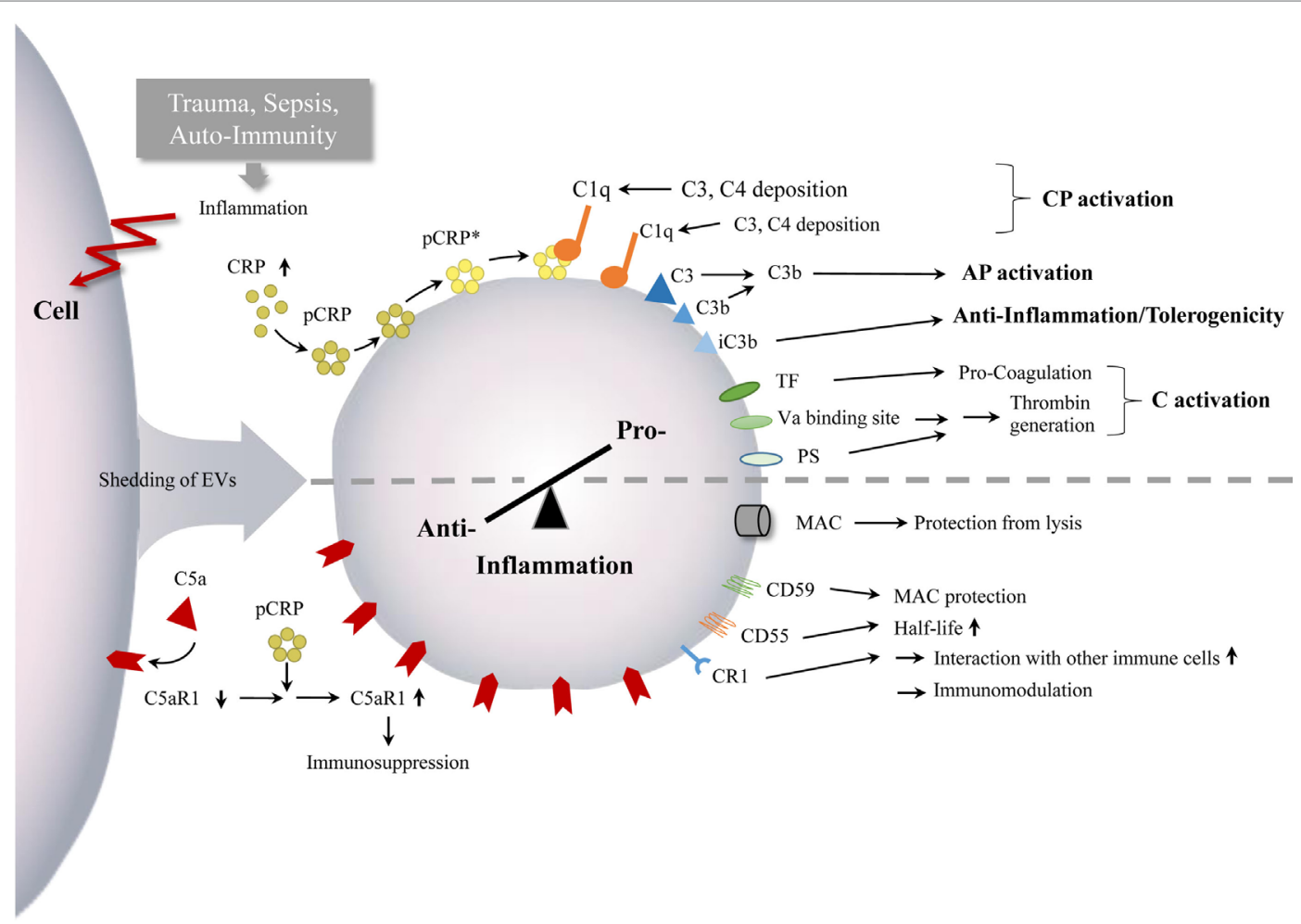

FIGURE 3 | Interaction between EVs and complement. Inflammatory conditions, after trauma, during sepsis as well as in auto-immunity, can lead to enhanced numbers of circulating EVs with complement components. The EVs appear to mediate both complement activation and inhibition, which can monitor or ship the pro-anti-inflammatory immune balance and inflammatory processes, indicated by the semi-dotted line. Abbreviations: AP, alternative pathway; C, complement; CP, classical pathway; CR1, complement receptor 1; CRP, C - reactive protein; mCRP, monomeric CRP; pCRP, pentameric CRP, pCRP*, pentameric CRP, expressing neoepitope of mCRP; PS, phosphatidylserine; TF, tissue factor.

the view of the tumor, EVs can also function as packages "ingrata", where they expel therapeutics out of the cancer cell by MV shedding mechanisms (122).

Established mechanisms for tumor progression include degradation of extracellular matrix components, resulting in barrier dysfunction, tumor invasion, and tumor cell migration $(123,124)$. In this regard, tumor-derived EVs harbor matrix-degradation proteases including matrix metalloproteinase-2 (MMP-2) and MMP-9, which correlated with tumor progression $(125,126)$. Furthermore, tumor cells have been shown to exploit EVs to contribute to their progression by inactivating $\mathrm{T}$ lymphocytes or natural killer cells as well as promoting differentiation of regulatory T lymphocytes to suppress immune reactions (127).

In summary, the main known mechanisms of EVs provide degradation of extracellular matrix components, transfer of oncogenic activity to other cancer cells, and drug resistance $(7,121,122)$.

\section{Inflammatory Diseases}

In the context of inflammation, EVs have been shown to exert both pro- and anti-inflammatory effects and can influence the course of disease. In particular, MVs can not only modulate inflammation but also coagulation. MV production dramatically increases after severe trauma, including traumatic brain injury (TBI), major burn injury, and during sepsis (128-130).
In regard of severe sepsis, complement is known to negatively influence the immune response, which can even lead to multiorgan failure (131). Non-survivors of septic shock for example, exhibit increased numbers of MVs bearing C5aR in comparison with sepsis survivors (10). Simultaneously, C5aR expression on neutrophils completely mirrored the expression pattern on MVs, displaying a loss of $\mathrm{C} 5 \mathrm{aR}$ on neutrophils in patients who did not survive the lethal consequences of sepsis (10).

Noteworthy, EVs also play critical roles in TBI (132). Similar to other injuries, cell-cell communication is critical for regulating the immune response in TBI (133). TBI features a post-inflammatory immune response, which results in the activation and migration of resident glia and of recruited peripheral immune cells to the injury site (134). Kumar et al. recently found that microglialderived MVs are responsible for neuroinflammation after TBI (135). In a rodent TBI model, EVs were isolated after injury and revealed an altered expression pattern of miRNA. Expression of miR-212 in EVs decreased, while miR-21, miR-146, miR-7a, and miR-7b were significantly increased after injury, indicating an enhancement loop of neuroinflammation caused by EVs (136).

Extracellular vesicles also modulate ocular immune functions in health and in disease, and they are associated with inflammatory conditions in AMD (137). Additionally, dysregulation of the alternative pathway with consequent over-activation of complement critically influences the pathophysiology of AMD 
(90, 138). RPE-derived exosomes appear as contributors of inflammation by interacting with complement. Aged mouse RPE cells and human RPE cell lines shed exosomes containing $\mathrm{C} 3$ and FH on their surfaces (93). Additionally, the complement regulators CD55 and CD59 were detected on RPE-derived EVs, enhancing complement attack of the parent cells (89). However, it is still unclear how RPE-derived EVs modulate AMD-related complement responses. Overall, EVs represent a highly promising research area not only for the field of ocular diseases. In future approaches, EVs from other ocular cell populations should be analyzed for their contribution to inflammation. For example, corneal fibroblasts are already described to release exosomes, which contain components of the extracellular matrix, which are important for corneal wound healing (139).

\section{Neurodegenerative Disorders}

Extracellular vesicles inhere multiple and crucial functions in the central nervous system (CNS), including intercellular communication, maintenance of myelination, synaptic plasticity, antigen presentation, and trophic support of neurons, which are reviewed in detail elsewhere (140). It is unsurprising that EVs are associated with amyotrophic lateral sclerosis (ALS), Alzheimer's disease or Parkinson's disease, where they can act as carriers of misfolded and neurodegenerative-specific proteins. For example, TAR DNA binding protein (TDP-43) is one of the main pathogenic proteins contributing to ALS (141). Ubiquitinated and hyperphosphorylated abnormal TDP-43 fragments are described to accumulate as vesicle inclusions within neurons and glia, causing cellular death $(141,142)$. Interestingly, TDP-43-enriched EVs could be extracted from ALS patients, suggesting a crucial impact on the course of disease (143). A detailed account of these findings as well as others, considering the role of EVs in neurodegeneration, is highlighted in a comprehensive review (144). Regarding the role of complement, investigations so far are lacking that link EVs with complement in neurodegenerative disorders.

\section{EVs As Potential Biomarkers}

Extracellular vesicles represent multifunctional entities that appear to play an active role in many biological processes, including the transfer of bioactive molecules between cells and tissues, and the transfer of viruses and prions $(145,146)$.

Extracellular vesicles, including exosomes and MVs, have promising properties as minimally invasive and novel source of biomaterial in molecular diagnostics (147). Furthermore, EVs can be readily identified and collected from various biological fluids. EVs carry a variety of macromolecules, including DNA, RNA, mRNA, miRNA, and other non-coding RNAs, as well as complement, providing promising targets for disease detection, characterization, monitoring, and therapy. Clinically, circulating exosomes and MVs isolated from cancer patients have been associated with metastasis or relapse, and thus could serve as important diagnostic and prognostic markers as well as therapeutic targets (148). Furthermore, tumor-derived MVs have been described to contain tumor-gene transcripts, which could be used as "liquid biopsies" in the field of clinical diagnostic (149).

In the context of neurodegenerative diseases, there remains a lack of biomarkers, particularly neurodegenerative-specific biomarkers are difficult to detect in CSF (150). Because CNSderived EVs are described, the fact that they protect their cargo from degradation makes them promising candidates as biomarkers (1). As an additional advantage, the cellular origin can be identified according to surface marker expression profiles (151). Thereby, EVs may help to deliver more knowledge about the cellular and pathogenic processes in specific CNS cell populations. MVs spiked with complement may represent attractive biomarkers to analyze the inflammatory state in patients, including $\mathrm{C} 5 \mathrm{aR}$, which on MVs correlates with the severity of sepsis outcome (10). However, no standardized method for $\mathrm{EV}$ isolation and characterization is established in the clinical application (152).

\section{EVs As Therapeutic Vehicles}

In the field of translational medicine, EVs represent promising candidates for therapeutic applications, for example, as vehicles for horizontal molecule transfer. Additionally, they inhere a myriad of potential clinical applications, ranging from oncological destruction to tissue repair and regeneration $(42,153)$.

Because vesicles can pass the blood-brain barrier (BBB), they could even be considered as naturally occurring liposomes (154). This aspect is of immense importance for pathologies concerning the CNS, including TBI, neurodegeneration and brain cancer, where the BBB dramatically limits drug delivery (155).

As the natural carrier of signal molecules, EVs possess many other favorable properties including stability, biocompatibility, biological barrier penetration, low toxicity, which make them an attractive vehicle for therapeutic delivery (156). Moreover, exosomes may be less immunogenic, less cytotoxic, and nonmutagenic compared to other existing viral-based or liposomebased gene delivery vehicles (157). These characteristics suggest that exosomes can be developed as an ideal vehicle for therapeutic delivery. Because EVs use native mechanisms for cellular entry, internalization and trafficking, therapeutics in the form of small RNA could benefit from EV delivery, including miRNAs, antiinflammatory agents, and anti-cancer drugs. Tumor acidity is a key contributor to chemo-resistance by protonation and subsequent neutralization in the acidic microenvironment (63). Drug transfer by EVs may overcome this situation and could facilitate an efficient transport of the drug into the tumor cells. To date, the feasibility of EV-based therapies has not been evaluated in clinical trials because there are some major limitations for therapeutic application.

Extracellular vesicles, particularly MVs, contain PS on their surfaces, initiating complement activation and subsequent rapid clearance. Thus, introducing modification of vesicles appear to be inevitable but also therapeutically promising (69). In this context, the design of EVs harboring complement regulators, including CR1 or CD55 as well as CD59, might protect them against complement activation and attack, and thereby prolong their half-life in the circulation and ensure a wide-range systemic distribution, all of which may be of advantage in the treatment of systemic inflammatory conditions. However, PS is also known to induce thrombosis by activating the coagulation cascade, resulting in adverse thrombotic events after clinical application (94). In this case, myristoylated 
alanine-rich C-kinase substrate (MARCKS) appears to be a promising option, because in vitro studies have demonstrated that MARCKS can sense PS and inhibit its functions, and thus may act as an anticoagulant agent (158). Therefore, it would be promising to investigate whether MARCKS is able to inhibit complement activation and/or thrombosis. In addition to cargo delivery, this finding is also of importance for targeting PS-containing MVs, which are for example present in circulating cancer-derived EVs from various cancers and can induce thrombotic events (159).

Unmodified EVs are prone to accumulation, which preferentially occurs in solid organs, including the liver, kidney, and spleen, and consequently results in rapid clearance by bile excretion, renal filtration, or phagocytosis. Therefore, the therapeutic cargoes within EVs might reveal a minimal accumulation in the intended tissue or organs and may instead be enriched in un-intended tissues $(160,161)$. This bio-distribution profile and off-target effects also disqualify unmodified exosomes from clinically acceptable therapeutics. Though, EVs need modifications to improve their physiochemical properties and therapeutic efficiency. PEGylation of EVs has been analyzed in mice, where they displayed improved cell specificity and prolonged circulation times (162). Nevertheless, PEGylated EVs are still subject to rapid clearance as a result of systemic immunogenicity (163). How EVs target recipient cells in vivo remains largely unknown. However, exosomes are selectively enriched in some transmembrane proteins that can be genetically engineered to display ligands/homing peptides on their surface, which confers exosome binding specificity to cells bearing the related receptors (164). Innovative technologies, including phage display and in vivo biopanning helped to discover many peptides homing to diseased tissues or organs, providing a potential use for targeted EV-therapy (164). Furthermore, lipid composition also plays an important role for favorable physiochemical properties, influencing vesicle uptake, bio-distribution, and half-life in the organism $(1,23)$. Therefore, this aspect should be considered for vehicle engineering and may be important for the improvement of liposomal drug delivery systems (161). However, therapeutic application of liposomal drug delivery systems are known to be able to induce a complement activation related pseudoallergy (CARPA), hampering their clinical use (165). The extent of CARPA by liposomes depends on several characteristics, including charge, size, and cholesterol content (166). In contrast to liposomes, EVs have conserved membranous structures, including natural corona, lipid composition, (trans-) membrane proteins, receptors as well as uptake and fusion modalities, which are comparable to those in cells (165). Thus, EVs seem to overcome the CARPA limitations caused by liposomes or nanoparticle-based delivery systems and represent highly promising therapeutic carriers (167).

In the context of inflammation, a noninvasive application of EVs containing anti-inflammatory drugs resulted in a significant inhibition of lipopolysaccharide (LPS)-induced brain inflammation in rodents (168). In a pioneering study, the use of nitrogen cavitation effectively generated a large number of EVs from neutrophils. Strikingly, this artificially generated EVs displayed more favorable properties compared to normal neutrophil-derived EVs, for example could also deliver an anti-inflammatory drug, which successfully showed beneficial effects in acute lung inflammation/injury and in LPS-induced sepsis (169). Hypothetically, such EVs could be used for therapeutic targeting of complement, by engineering EVs with specific binding sites for complement molecules to scavenge excessive soluble complement factors from the blood circulation and protect the host from overwhelming complement activation, for example in the clinical setting of severe trauma or sepsis. Furthermore, RPE-derived EV s also represent therapeutic vesicles for the treatment of inflammatory conditions including eye diseases. They are able to induce monocyte death or reprogram monocytes toward an anti-inflammatory phenotype (170).

\section{CONCLUSION}

During recent decades, EVs have gained an emerging interest for both scientists and clinicians. Several studies have been conducted to obtain greater knowledge about the content of EVs, mechanisms of their biogenesis, functions, and involvement in diseases. As key players in pro- and anti-inflammatory events, EVs are of importance for the immune response and regulation $(8,42,45)$. EV levels are enhanced in inflammatory diseases, particularly where complement activation occurs in a dysregulated manner, including polytrauma, TBI, hemorrhage, and septic shock $(10,36)$. The co-occurrence of EVs and complement indicate an important link in the context of innate immune responses. Current data gained from cellular experiments and clinical observations have confirmed that released EVs carry and modulate complement, and vice versa complement is also able to influence the number of circulating vesicles (Figure 3). Nevertheless, studies addressing this area of research are rare and thus, further scientific and clinical investigations are necessary for a deeper insight into the precise mechanistic interactions between complement and vesicles. In conclusion, EVs exhibit the potential as biomarkers and targets as well as therapeutic agents for complement and immunomodulatory strategies in the field of translational and personalized medicine, which are relevant in a broad scope of inflammatory diseases.

\section{AUTHOR CONTRIBUTIONS}

EK wrote the manuscript with the help from MH-L. All authors edited and commented on the manuscript. All authors read and approved the final manuscript.

\section{ACKNOWLEDGMENTS}

We thank Dr. Stephanie Denk for graphical support.

\section{FUNDING}

This work is supported by grants from the German Research Foundation (DFG) to SE. and MH-L. (EI 866/5-1). SE. is a Heisenberg-Professor of the DFG (EI 866/4-1). 


\section{REFERENCES}

1. Yanez-Mo M, Siljander PR, Andreu Z, Zavec AB, Borras FE, Buzas EI, et al. Biological properties of extracellular vesicles and their physiological functions. J Extracell Vesicles (2015) 4:27066. doi:10.3402/jev.v4.27066

2. Schwechheimer C, Kuehn MJ. Outer-membrane vesicles from gram-negative bacteria: biogenesis and functions. Nat Rev Microbiol (2015) 13(10):605-19. doi:10.1038/nrmicro3525

3. Ellis TN, Kuehn MJ. Virulence and immunomodulatory roles of bacterial outer membrane vesicles. Microbiol Mol Biol Rev (2010) 74(1):81-94. doi:10.1128/ MMBR.00031-09

4. Mashburn LM, Whiteley M. Membrane vesicles traffic signals and facilitate group activities in a prokaryote. Nature (2005) 437(7057):422-5. doi:10.1038/ nature 03925

5. Rutter BD, Innes RW. Extracellular vesicles isolated from the leaf apoplast carry stress-response proteins. Plant Physiol (2017) 173(1):728-41. doi:10.1104/ pp. 16.01253

6. Taraboletti G, D’Ascenzo S, Borsotti P, Giavazzi R, Pavan A, Dolo V. Shedding of the matrix metalloproteinases MMP-2, MMP-9, and MT1-MMP as membrane vesicle-associated components by endothelial cells. Am J Pathol (2002) 160(2):673-80. doi:10.1016/S0002-9440(10)64887-0

7. D’Asti E, Garnier D, Lee TH, Montermini L, Meehan B, Rak J. Oncogenic extracellular vesicles in brain tumor progression. Front Physiol (2012) 3:294. doi:10.3389/fphys.2012.00294

8. Robbins PD, Morelli AE. Regulation of immune responses by extracellular vesicles. Nat Rev Immunol (2014) 14(3):195-208. doi:10.1038/nri3622

9. Karpman D, Stahl AL, Arvidsson I, Johansson K, Loos S, Tati R, et al. Complement interactions with blood cells, endothelial cells and microvesicles in thrombotic and inflammatory conditions. Adv Exp Med Biol (2015) 865:19-42. doi:10.1007/978-3-319-18603-0_2

10. Unnewehr H, Rittirsch D, Sarma JV, Zetoune F, Flierl MA, Perl M, et al. Changes and regulation of the $\mathrm{C} 5 \mathrm{a}$ receptor on neutrophils during septic shock in humans. J Immunol (2013) 190(8):4215-25. doi:10.4049/jimmunol. 1200534

11. Biro E, Nieuwland R, Tak PP, Pronk LM, Schaap MC, Sturk A, et al. Activated complement components and complement activator molecules on the surface of cell-derived microparticles in patients with rheumatoid arthritis and healthy individuals. Ann Rheum Dis (2007) 66(8):1085-92. doi:10.1136/ ard.2006.061309

12. Kerr JF, Wyllie AH, Currie AR. Apoptosis: a basic biological phenomenon with wide-ranging implications in tissue kinetics. Br J Cancer (1972) 26(4):239-57. doi:10.1038/bjc.1972.33

13. Hacker G. The morphology of apoptosis. Cell Tissue Res (2000) 301(1):5-17. doi:10.1007/s004410000193

14. Borges FT, Reis LA, Schor N. Extracellular vesicles: structure, function, and potential clinical uses in renal diseases. Braz J Med Biol Res (2013) 46(10):824-30. doi:10.1590/1414-431X20132964

15. Halicka HD, Bedner E, Darzynkiewicz Z. Segregation of RNA and separate packaging of DNA and RNA in apoptotic bodies during apoptosis. Exp Cell Res (2000) 260(2):248-56. doi:10.1006/excr.2000.5027

16. Lai CP, Breakefield XO. Role of exosomes/microvesicles in the nervous system and use in emerging therapies. Front Physiol (2012) 3:228. doi:10.3389/ fphys.2012.00228

17. Mathivanan S, Fahner CJ, Reid GE, Simpson RJ. ExoCarta 2012: database of exosomal proteins, RNA and lipids. Nucleic Acids Res (2012) 40(Database issue):D1241-4. doi:10.1093/nar/gkr828

18. Simpson RJ, Kalra H, Mathivanan S. ExoCarta as a resource for exosomal research. J Extracell Vesicles (2012) 1. doi:10.3402/jev.v1i0.18374

19. Tauro BJ, Greening DW, Mathias RA, Mathivanan S, Ji H, Simpson RJ. Two distinct populations of exosomes are released from LIM1863 colon carcinoma cell-derived organoids. Mol Cell Proteomics (2013) 12(3):587-98. doi:10.1074/ mcp.M112.021303

20. Cocucci E, Racchetti G, Meldolesi J. Shedding microvesicles: artefacts no more. Trends Cell Biol (2009) 19(2):43-51. doi:10.1016/j.tcb.2008.11.003

21. Haraszti RA, Didiot MC, Sapp E, Leszyk J, Shaffer SA, Rockwell HE, et al. High-resolution proteomic and lipidomic analysis of exosomes and microvesicles from different cell sources. J Extracell Vesicles (2016) 5:32570. doi:10.3402/jev.v5.32570
22. Hulsmans M, Holvoet P. MicroRNA-containing microvesicles regulating inflammation in association with atherosclerotic disease. Cardiovasc Res (2013) 100(1):7-18. doi:10.1093/cvr/cvt161

23. Kastelowitz N, Yin H. Exosomes and microvesicles: identification and targeting by particle size and lipid chemical probes. Chembiochem (2014) 15(7):923-8. doi:10.1002/cbic.201400043

24. Witwer KW, BuzasEI, Bemis LT, Bora A, Lasser C, LotvallJ, et al. Standardization of sample collection, isolation and analysis methods in extracellular vesicle research. J Extracell Vesicles (2013) 2. doi:10.3402/jev.v2i0.20360

25. Couzin J. Cell biology: the ins and outs of exosomes. Science (2005) 308(5730):1862-3. doi:10.1126/science.308.5730.1862

26. van der Pol E, Boing AN, Harrison P, Sturk A, Nieuwland R. Classification, functions, and clinical relevance of extracellular vesicles. Pharmacol Rev (2012) 64(3):676-705. doi:10.1124/pr.112.005983

27. Dumaswala UJ, Greenwalt TJ. Human erythrocytes shed exocytic vesicles in vivo. Transfusion (1984) 24(6):490-2. doi:10.1046/j.1537-2995.1984.24685066807.x

28. Takahashi A, Okada R, Nagao K, Kawamata Y, Hanyu A, Yoshimoto S, et al. Exosomes maintain cellular homeostasis by excreting harmful DNA from cells. Nat Commun (2017) 8:15287. doi:10.1038/ncomms15287

29. Falcone G, Felsani A, D’Agnano I. Signaling by exosomal microRNAs in cancer. J Exp Clin Cancer Res (2015) 34:32. doi:10.1186/s13046-015-0148-3

30. Abels ER, Breakefield XO. Introduction to extracellular vesicles: biogenesis, RNA cargo selection, content, release, and uptake. Cell Mol Neurobiol (2016) 36(3):301-12. doi:10.1007/s10571-016-0366-z

31. Lo CA, Stahl PD, Raposo G. Extracellular vesicles shuffling intercellular messages: for good or for bad. Curr Opin Cell Biol (2015) 35:69-77. doi:10.1016/j. ceb.2015.04.013

32. Ciardiello C, Cavallini L, Spinelli C, Yang J, Reis-Sobreiro M, de CP, et al. Focus on extracellular vesicles: new frontiers of cell-to-cell communication in cancer. Int J Mol Sci (2016) 17(2):175. doi:10.3390/ijms17020175

33. Wolf $\mathrm{P}$. The nature and significance of platelet products in human plasma. Br J Haematol (1967) 13(3):269-88. doi:10.1111/j.1365-2141.1967.tb08741.x

34. Hell L, Thaler J, Martinod K, Ay C, Posch F, Wagner DD, et al. OC-16 Neutrophil extracellular traps and tissue factor-bearing microvesicles: a liaison dangereuse causing overt DIC in cancer patients? Thromb Res (2016) 140(Suppl 1):S174-5. doi:10.1016/S0049-3848(16)30133-5

35. Gardiner C, Harrison P, Belting M, Boing A, Campello E, Carter BS, et al. Extracellular vesicles, tissue factor, cancer and thrombosis - discussion themes of the ISEV 2014 Educational Day. J Extracell Vesicles (2015) 4:26901. doi:10.3402/jev.v4.26901

36. Curry N, Raja A, Beavis J, Stanworth S, Harrison P. Levels of procoagulant microvesicles are elevated after traumatic injury and platelet microvesicles are negatively correlated with mortality. J Extracell Vesicles (2014) 3:25625. doi: $10.3402 /$ jev.v3.25625

37. Mackman N. The role of tissue factor and factor VIIa in hemostasis. Anesth Analg (2009) 108(5):1447-52. doi:10.1213/ane.0b013e31819bceb1

38. Del C I, Shrimpton CN, Thiagarajan P, Lopez JA. Tissue-factor-bearing microvesicles arise from lipid rafts and fuse with activated platelets to initiate coagulation. Blood (2005) 106(5):1604-11. doi:10.1182/blood-2004-03-1095

39. Fricke A, Ullrich PV, Cimniak AFV, Becherer C, Follo M, Heinz J, et al. Levels of activated platelet-derived microvesicles in patients with soft tissue sarcoma correlate with an increased risk of venous thromboembolism. BMC Cancer (2017) 17(1):527. doi:10.1186/s12885-017-3515-y

40. Hwang I. Cell-cell communication via extracellular membrane vesicles and its role in the immune response. Mol Cells (2013) 36(2):105-11. doi:10.1007/ s10059-013-0154-2

41. Maas SL, Breakefield XO, Weaver AM. Extracellular vesicles: unique intercellular delivery vehicles. Trends Cell Biol (2017) 27(3):172-88. doi:10.1016/j. tcb.2016.11.003

42. Sadallah S, Eken C, Schifferli JA. Ectosomes as immunomodulators. Semin Immunopathol (2011) 33(5):487-95. doi:10.1007/s00281-010-0232-x

43. Zitvogel L, Regnault A, Lozier A, Wolfers J, Flament C, Tenza D, et al. Eradication of established murine tumors using a novel cell-free vaccine: dendritic cell-derived exosomes. Nat Med (1998) 4(5):594-600. doi:10.1038/ nm0598-594

44. Raposo G, Nijman HW, Stoorvogel W, Liejendekker R, Harding CV, Melief CJ, et al. B lymphocytes secrete antigen-presenting vesicles. J Exp Med (1996) 183(3):1161-72. doi:10.1084/jem.183.3.1161 
45. Sadallah S, Eken C, Schifferli JA. Ectosomes as modulators of inflammation and immunity. Clin Exp Immunol (2011) 163(1):26-32. doi:10.1111/j.1365-2249. 2010.04271.x

46. Ismail N, Wang Y, Dakhlallah D, Moldovan L, Agarwal K, Batte K, et al. Macrophage microvesicles induce macrophage differentiation and miR-223 transfer. Blood (2013) 121(6):984-95. doi:10.1182/blood-2011-08-374793

47. Caby MP, Lankar D, Vincendeau-Scherrer C, Raposo G, Bonnerot C. Exosomal-like vesicles are present in human blood plasma. Int Immunol (2005) 17(7):879-87. doi:10.1093/intimm/dxh267

48. Huebner AR, Somparn P, Benjachat T, Leelahavanichkul A, Avihingsanon Y, Fenton RA, et al. Exosomes in urine biomarker discovery. Adv Exp Med Biol (2015) 845:43-58. doi:10.1007/978-94-017-9523-4_5

49. Ogawa Y, Miura Y, Harazono A, Kanai-Azuma M, Akimoto Y, Kawakami H, et al. Proteomic analysis of two types of exosomes in human whole saliva. Biol Pharm Bull (2011) 34(1):13-23. doi:10.1248/bpb.34.13

50. Admyre C, Johansson SM, Qazi KR, Filen JJ, Lahesmaa R, Norman M, et al. Exosomes with immune modulatory features are present in human breast milk. J Immunol (2007) 179(3):1969-78. doi:10.4049/jimmunol.179.3.1969

51. Asea A, Jean-Pierre C, Kaur P, Rao P, Linhares IM, Skupski D, et al. Heat shock protein-containing exosomes in mid-trimester amniotic fluids. J Reprod Immunol (2008) 79(1):12-7. doi:10.1016/j.jri.2008.06.001

52. Navabi H, Croston D, Hobot J, Clayton A, Zitvogel L, Jasani B, et al. Preparation of human ovarian cancer ascites-derived exosomes for a clinical trial. Blood Cells Mol Dis (2005) 35(2):149-52. doi:10.1016/j.bcmd.2005.06.008

53. Redzic JS, Ung TH, Graner MW. Glioblastoma extracellular vesicles: reservoirs of potential biomarkers. Pharmgenomics Pers Med (2014) 7:65-77. doi:10.2147/PGPM.S39768

54. Masyuk AI, Huang BQ, Ward CJ, Gradilone SA, Banales JM, Masyuk TV, et al. Biliary exosomes influence cholangiocyte regulatory mechanisms and proliferation through interaction with primary cilia. Am J Physiol Gastrointest Liver Physiol (2010) 299(4):G990-9. doi:10.1152/ajpgi.00093.2010

55. Aalberts $M$, van Dissel-Emiliani FM, van Adrichem NP, van WM, Wauben $\mathrm{MH}$, Stout TA, et al. Identification of distinct populations of prostasomes that differentially express prostate stem cell antigen, annexin A1, and GLIPR2 in humans. Biol Reprod (2012) 86(3):82. doi:10.1095/ biolreprod.111.095760

56. Saunderson SC, Dunn AC, Crocker PR, McLellan AD. CD169 mediates the capture of exosomes in spleen and lymph node. Blood (2014) 123(2):208-16. doi:10.1182/blood-2013-03-489732

57. Mack M, Kleinschmidt A, Bruhl H, Klier C, Nelson PJ, Cihak J, et al. Transfer of the chemokine receptor CCR5 between cells by membrane-derived microparticles: a mechanism for cellular human immunodeficiency virus 1 infection. Nat Med (2000) 6(7):769-75. doi:10.1038/77498

58. Montecalvo A, Shufesky WJ, Stolz DB, Sullivan MG, Wang Z, Divito SJ, et al. Exosomes as a short-range mechanism to spread alloantigen between dendritic cells during T cell allorecognition. J Immunol (2008) 180(5):3081-90. doi:10.4049/jimmunol.180.5.3081

59. Rank A, Nieuwland R, Crispin A, Grutzner S, Iberer M, Toth B, et al. Clearance of platelet microparticles in vivo. Platelets (2011) 22(2):111-6. doi:10.3109/ 09537104.2010.520373

60. Clayton A, Harris CL, Court J, Mason MD, Morgan BP. Antigen-presenting cell exosomes are protected from complement-mediated lysis by expression of CD55 and CD59. Eur JImmunol (2003) 33(2):522-31. doi:10.1002/ immu.200310028

61. Pilzer D, Gasser O, Moskovich O, Schifferli JA, Fishelson Z. Emission of membrane vesicles: roles in complement resistance, immunity and cancer. Springer Semin Immunopathol (2005) 27(3):375-87. doi:10.1007/s00281-005-0004-1

62. Mulcahy LA, Pink RC, Carter DR. Routes and mechanisms of extracellular vesicle uptake. J Extracell Vesicles (2014) 3. doi:10.3402/jev.v3.24641

63. Parolini I, Federici C, Raggi C, Lugini L, Palleschi S, De MA, et al. Microenvironmental $\mathrm{pH}$ is a key factor for exosome traffic in tumor cells. J Biol Chem (2009) 284(49):34211-22. doi:10.1074/jbc.M109.041152

64. Ricklin D, Hajishengallis G, Yang K, Lambris JD. Complement: a key system for immune surveillance and homeostasis. Nat Immunol (2010) 11(9):785-97. doi:10.1038/ni.1923

65. Ehrnthaller C, Ignatius A, Gebhard F, Huber-Lang M. New insights of an old defense system: structure, function, and clinical relevance of the complement system. Mol Med (2011) 17(3-4):317-29. doi:10.2119/molmed.2010.00149
66. Huber-Lang M, Kovtun A, Ignatius A. The role of complement in trauma and fracture healing. Semin Immunol (2013) 25(1):73-8. doi:10.1016/j. smim.2013.05.006

67. Roselli F, Karasu E, Volpe C, Huber-Lang M. Medusa's head: the complement system in traumatic brain and spinal cord injury. J Neurotrauma (2018) 35(2):226-40. doi:10.1089/neu.2017.5168

68. Klos A, Tenner AJ, Johswich KO, Ager RR, Reis ES, Kohl J. The role of the anaphylatoxins in health and disease. Mol Immunol (2009) 46(14):2753-66. doi:10.1016/j.molimm.2009.04.027

69. Zecher D, Cumpelik A, Schifferli JA. Erythrocyte-derived microvesicles amplify systemic inflammation by thrombin-dependent activation of complement. Arterioscler Thromb Vasc Biol (2014) 34(2):313-20. doi:10.1161/ ATVBAHA.113.302378

70. Stein JM, Luzio JP. Ectocytosis caused by sublytic autologous complement attack on human neutrophils. The sorting of endogenous plasma-membrane proteins and lipids into shed vesicles. Biochem J (1991) 274(Pt 2):381-6. doi:10.1042/bj2740381

71. Ohanian SH, Schlager SI, Borsos T. Molecular interactions of cells with antibody and complement: influence of metabolic and physical properties of the target on the outcome of humoral immune attack. Contemp Top Mol Immunol (1978) 7:153-80. doi:10.1007/978-1-4757-0779-3_5

72. Hess C, Sadallah S, Hefti A, Landmann R, Schifferli JA. Ectosomes released by human neutrophils are specialized functional units. JImmunol (1999) 163(8):4564-73.

73. Carney DF, Hammer CH, Shin ML. Elimination of terminal complement complexes in the plasma membrane of nucleated cells: influence of extracellular Ca2+ and association with cellular Ca2+. J Immunol (1986) 137(1):263-70.

74. Morgan BP, Dankert JR, Esser AF. Recovery of human neutrophils from complement attack: removal of the membrane attack complex by endocytosis and exocytosis. J Immunol (1987) 138(1):246-53.

75. Ramm LE, Whitlow MB, Koski CL, Shin ML, Mayer MM. Elimination of complement channels from the plasma membranes of U937, a nucleated mammalian cell line: temperature dependence of the elimination rate. J Immunol (1983) 131(3):1411-5.

76. Iida K, Whitlow MB, Nussenzweig V. Membrane vesiculation protects erythrocytes from destruction by complement. J Immunol (1991) 147(8):2638-42.

77. Morgan BP, Imagawa DK, Dankert JR, Ramm LE. Complement lysis of U937, a nucleated mammalian cell line in the absence of C9: effect of C9 on C5b-8 mediated cell lysis. J Immunol (1986) 136(9):3402-6.

78. Scolding NJ, Morgan BP, Houston A, Campbell AK, Linington C, Compston DA Normal rat serum cytotoxicity against syngeneic oligodendrocytes Complement activation and attack in the absence of anti-myelin antibodies. J Neurol Sci (1989) 89(2-3):289-300. doi:10.1016/0022-510X(89) 90030-0

79. Scolding NJ, Morgan BP, Houston WA, Linington C, Campbell AK, Compston DA. Vesicular removal by oligodendrocytes of membrane attack complexes formed by activated complement. Nature (1989) 339(6226):620-2. doi:10.1038/339620a0

80. Liu D, Liu F, Song YK. Recognition and clearance of liposomes containing phosphatidylserine are mediated by serum opsonin. Biochim Biophys Acta (1995) 1235(1):140-6. doi:10.1016/0005-2736(95)00005-N

81. Srinath P, Vyas SP, Diwan PV. Preparation and pharmacodynamic evaluation of liposomes of indomethacin. Drug Dev Ind Pharm (2000) 26(3):313-21. doi:10.1081/DDC-100100359

82. Bradley AJ, Brooks DE, Norris-Jones R, Devine DV. C1q binding to liposomes is surface charge dependent and is inhibited by peptides consisting of residues 14-26 of the human C1qA chain in a sequence independent manner. Biochim Biophys Acta (1999) 1418(1):19-30. doi:10.1016/S0005-2736(99)00013-9

83. Brodbeck WG, Kuttner-Kondo L, Mold C, Medof ME. Structure/function studies of human decay-accelerating factor. Immunology (2000) 101(1): 104-11. doi:10.1046/j.1365-2567.2000.00086.x

84. Meri S, Morgan BP, Davies A, Daniels RH, Olavesen MG, Waldmann H, et al. Human protectin (CD59), an 18,000-20,000 MW complement lysis restricting factor, inhibits C5b-8 catalysed insertion of C9 into lipid bilayers. Immunology (1990) 71(1):1-9.

85. Gasser O, Schifferli JA. Microparticles released by human neutrophils adhere to erythrocytes in the presence of complement. Exp Cell Res (2005) 307(2):381-7. doi:10.1016/j.yexcr.2005.03.011 
86. Schifferli JA, Taylor RP. Physiological and pathological aspects of circulating immune complexes. Kidney Int (1989) 35(4):993-1003. doi:10.1038/ ki. 1989.83

87. Schifferli JA, Paccaud JP. Complement and its receptor: a physiological transport system for circulating immune complexes. Contrib Nephrol (1989) 69:1-8. doi:10.1159/000416739

88. Pascual M, Lutz HU, Steiger G, Stammler P, Schifferli JA. Release of vesicles enriched in complement receptor 1 from human erythrocytes. J Immunol (1993) 151(1):397-404.

89. Ebrahimi KB, Fijalkowski N, Cano M, Handa JT. Decreased membrane complement regulators in the retinal pigmented epithelium contributes to agerelated macular degeneration. J Pathol (2013) 229(5):729-42. doi:10.1002/ path. 4128

90. Skerka C, Lauer N, Weinberger AA, Keilhauer CN, Suhnel J, Smith R, et al. Defective complement control of factor $\mathrm{H}(\mathrm{Y} 402 \mathrm{H})$ and FHL-1 in age-related macular degeneration. Mol Immunol (2007) 44(13):3398-406. doi:10.1016/j. molimm.2007.06.018

91. Haines JL, Hauser MA, Schmidt S, Scott WK, Olson LM, Gallins P, et al. Complement factor $\mathrm{H}$ variant increases the risk of age-related macular degeneration. Science (2005) 308(5720):419-21. doi:10.1126/science.1110359

92. Edwards AO, Ritter R III, Abel KJ, Manning A, Panhuysen C, Farrer LA. Complement factor $\mathrm{H}$ polymorphism and age-related macular degeneration. Science (2005) 308(5720):421-4. doi:10.1126/science.1110189

93. Wang AL, Lukas TJ, Yuan M, Du N, Tso MO, Neufeld AH. Autophagy and exosomes in the aged retinal pigment epithelium: possible relevance to drusen formation and age-related macular degeneration. PLoS One (2009) 4(1):e4160. doi:10.1371/journal.pone.0004160

94. Burk AM, Martin M, Flierl MA, Rittirsch D, Helm M, Lampl L, et al. Early complementopathy after multiple injuries in humans. Shock (2012) 37(4):348-54. doi:10.1097/SHK.0b013e3182471795

95. Frith D, Davenport R, Brohi K. Acute traumatic coagulopathy. Curr Opin Anaesthesiol (2012) 25(2):229-34. doi:10.1097/ACO.0b013e3283509675

96. Frith D, Goslings JC, Gaarder C, Maegele M, Cohen MJ, Allard S, et al. Definition and drivers of acute traumatic coagulopathy: clinical and experimental investigations. J Thromb Haemost (2010) 8(9):1919-25. doi:10.1111/j.1538-7836.2010.03945.x

97. Kalkoff M, Cursons RT, Sleigh JW, Jacobson GM. The use of real time rtPCR to quantify inflammatory mediator expression in leukocytes from patients with severe sepsis. Anaesth Intensive Care (2004) 32(6):746-55.

98. Morel O, Morel N, Jesel L, Freyssinet JM, Toti F. Microparticles: a critical component in the nexus between inflammation, immunity, and thrombosis. Semin Immunopathol (2011) 33(5):469-86. doi:10.1007/s00281-010-0239-3

99. Sadallah S, Eken C, Schifferli JA. Erythrocyte-derived ectosomes have immunosuppressive properties. J Leukoc Biol (2008) 84(5):1316-25. doi:10.1189/ jlb.0108013

100. Ricklin D, Lambris JD. Complement in immune and inflammatory disorders: pathophysiological mechanisms. JImmunol (2013) 190(8):3831-8. doi:10.4049/jimmunol.1203200

101. Volanakis JE. Human C-reactive protein: expression, structure, and function. Mol Immunol (2001) 38(2-3):189-97. doi:10.1016/S0161-5890(01)00042-6

102. Braig D, Nero TL, Koch HG, Kaiser B, Wang X, Thiele JR, et al. Transitional changes in the CRP structure lead to the exposure of proinflammatory binding sites. Nat Commun (2017) 8:14188. doi:10.1038/ncomms14188

103. Thiele JR, Habersberger J, Braig D, Schmidt Y, Goerendt K, Maurer V, et al. Dissociation of pentameric to monomeric C-reactive protein localizes and aggravates inflammation: in vivo proof of a powerful proinflammatory mechanism and a new anti-inflammatory strategy. Circulation (2014) 130(1):35-50. doi:10.1161/CIRCULATIONAHA.113.007124

104. Braig D, Kaiser B, Thiele JR, Bannasch H, Peter K, Stark GB, et al. A conformational change of $\mathrm{C}$-reactive protein in burn wounds unmasks its proinflammatory properties. Int Immunol (2014) 26(8):467-78. doi:10.1093/ intimm/dxu056

105. Habersberger J, Strang F, Scheichl A, Htun N, Bassler N, Merivirta RM, et al. Circulating microparticles generate and transport monomeric C-reactive protein in patients with myocardial infarction. Cardiovasc Res (2012) 96(1):64-72. doi:10.1093/cvr/cvs237

106. Sohn JH, Bora PS, Suk HJ, Molina H, Kaplan HJ, Bora NS. Tolerance is dependent on complement $\mathrm{C} 3$ fragment iC3b binding to antigen-presenting cells. Nat Med (2003) 9(2):206-12. doi:10.1038/nm814
107. Barbour TD, Ling GS, Ruseva MM, Fossati-Jimack L, Cook HT, Botto M, et al. Complement receptor 3 mediates renal protection in experimental C3 glomerulopathy. Kidney Int (2016) 89(4):823-32. doi:10.1016/j.kint.2015. 11.024

108. Gershov D, Kim S, Brot N, Elkon KB. C-Reactive protein binds to apoptotic cells, protects the cells from assembly of the terminal complement components, and sustains an antiinflammatory innate immune response: implications for systemic autoimmunity. J Exp Med (2000) 192(9):1353-64. doi:10.1084/ jem.192.9.1353

109. Mevorach D, Mascarenhas JO, Gershov D, Elkon KB. Complementdependent clearance of apoptotic cells by human macrophages. J Exp Med (1998) 188(12):2313-20. doi:10.1084/jem.188.12.2313

110. Swinkels M, Zhang JH, Tilakaratna V, Black G, Perveen R, McHarg S, et al. $\mathrm{C}$-reactive protein and pentraxin- 3 binding of factor $\mathrm{H}$-like protein 1 differs from complement factor $\mathrm{H}$ : implications for retinal inflammation. Sci Rep (2018) 8(1):1643. doi:10.1038/s41598-017-18395-7

111. Chudwin DS, Papierniak C, Lint TF, Korenblit AD. Activation of the alternative complement pathway by red blood cells from patients with sickle cell disease. Clin Immunol Immunopathol (1994) 71(2):199-202. doi:10.1006/ clin.1994.1072

112. Sweeney J, Kouttab N, Kurtis J. Stored red blood cell supernatant facilitates thrombin generation. Transfusion (2009) 49(8):1569-79. doi:10.1111/j. 1537-2995.2009.02196.x

113. Acosta J, Qin X, Halperin J. Complement and complement regulatory proteins as potential molecular targets for vascular diseases. Curr Pharm Des (2004) 10(2):203-11. doi:10.2174/1381612043453441

114. Langeggen H, Pausa M, Johnson E, Casarsa C, Tedesco F. The endothelium is an extrahepatic site of synthesis of the seventh component of the complement system. Clin Exp Immunol (2000) 121(1):69-76. doi:10.1046/j.1365-2249. 2000.01238.x

115. Hamilton KK, Hattori R, Esmon CT, Sims PJ. Complement proteins C5b-9 induce vesiculation of the endothelial plasma membrane and expose catalytic surface for assembly of the prothrombinase enzyme complex. J Biol Chem (1990) 265(7):3809-14.

116. Walker RK, Krishnaswamy S. The activation of prothrombin by the prothrombinase complex. The contribution of the substrate-membrane interaction to catalysis. J Biol Chem (1994) 269(44):27441-50.

117. Huber-Lang M, Sarma JV, Zetoune FS, Rittirsch D, Neff TA, McGuire SR, et al. Generation of $\mathrm{C} 5 \mathrm{a}$ in the absence of $\mathrm{C} 3$ : a new complement activation pathway. Nat Med (2006) 12(6):682-7. doi:10.1038/nm1419

118. Butenas S, Branda RF, van't Veer C, Cawthern KM, Mann KG. Platelets and phospholipids in tissue factor-initiated thrombin generation. Thromb Haemost (2001) 86(2):660-7. doi:10.1055/s-0037-1616110

119. Amara U, Rittirsch D, Flierl M, Bruckner U, Klos A, Gebhard F, et al. Interaction between the coagulation and complement system. Adv Exp Med Biol (2008) 632:71-9.

120. Orfeo T, Butenas S, Brummel-Ziedins KE, Mann KG. The tissue factor requirement in blood coagulation. J Biol Chem (2005) 280(52):42887-96. doi:10.1074/jbc.M505506200

121. Al-Nedawi K, Meehan B, Micallef J, Lhotak V, May L, Guha A, et al. Intercellular transfer of the oncogenic receptor EGFRvIII by microvesicles derived from tumour cells. Nat Cell Biol (2008) 10(5):619-24. doi:10.1038/ ncb 1725

122. Muralidharan-Chari V, Kohan HG, Asimakopoulos AG, Sudha T, Sell S, Kannan K, et al. Microvesicle removal of anticancer drugs contributes to drug resistance in human pancreatic cancer cells. Oncotarget (2016) 7(31):50365-79. doi:10.18632/oncotarget.10395

123. Quaranta V. Cell migration through extracellular matrix: membrane-type metalloproteinases make the way. J Cell Biol (2000) 149(6):1167-70. doi:10.1083/jcb.149.6.1167

124. Shen Q, Lee ES, Pitts RL, Wu MH, Yuan SY. Tissue inhibitor of metalloproteinase-2 regulates matrix metalloproteinase-2-mediated endothelial barrier dysfunction and breast cancer cell transmigration through lung microvascular endothelial cells. Mol Cancer Res (2010) 8(7):939-51. doi:10.1158/15417786.MCR-09-0523

125. Dolo V, Ginestra A, Cassara D, Violini S, Lucania G, Torrisi MR, et al. Selective localization of matrix metalloproteinase 9, betal integrins, and human lymphocyte antigen class I molecules on membrane vesicles shed by 8701-BC breast carcinoma cells. Cancer Res (1998) 58(19):4468-74. 
126. Ginestra A, La Placa MD, Saladino F, Cassara D, Nagase H, Vittorelli ML. The amount and proteolytic content of vesicles shed by human cancer cell lines correlates with their in vitro invasiveness. Anticancer Res (1998) 18(5A):3433-7.

127. Valenti R, Huber V, Iero M, Filipazzi P, Parmiani G, Rivoltini L. Tumorreleased microvesicles as vehicles of immunosuppression. Cancer Res (2007) 67(7):2912-5. doi:10.1158/0008-5472.CAN-07-0520

128. Ogura H, Kawasaki T, Tanaka H, Koh T, Tanaka R, Ozeki Y, et al. Activated platelets enhance microparticle formation and platelet-leukocyte interaction in severe trauma and sepsis. J Trauma (2001) 50(5):801-9. doi:10.1097/00005373-200105000-00005

129. O’Dea KP, Porter JR, Tirlapur N, Katbeh U, Singh S, Handy JM, et al. Circulating microvesicles are elevated acutely following major burns injury and associated with clinical severity. PLoS One (2016) 11(12):e0167801. doi:10.1371/journal.pone.0167801

130. Lehner GF, Harler U, Haller VM, Feistritzer C, Hasslacher J, Dunzendorfer S, et al. Characterization of microvesicles in septic shock using highsensitivity flow cytometry. Shock (2016) 46(4):373-81. doi:10.1097/SHK. 0000000000000657

131. Rittirsch D, Redl H, Huber-Lang M. Role of complement in multiorgan failure. Clin Dev Immunol (2012) 2012:962927. doi:10.1155/2012/962927

132. Hazelton I, Yates A, Dale A, Roodselaar J, Akbar N, Ruitenberg MJ, et al. Exacerbation of acute traumatic brain injury by circulating extracellular vesicles. J Neurotrauma (2018) 35(4):639-51. doi:10.1089/ neu.2017.5049

133. Gyoneva S, Ransohoff RM. Inflammatory reaction after traumatic brain injury: therapeutic potential of targeting cell-cell communication by chemokines. Trends Pharmacol Sci (2015) 36(7):471-80. doi:10.1016/j.tips. 2015.04.003

134. Russo MV, McGavern DB. Immune surveillance of the CNS following Infection and Injury. Trends Immunol (2015) 36(10):637-50. doi:10.1016/j. it.2015.08.002

135. Kumar A, Stoica BA, Loane DJ, Yang M, Abulwerdi G, Khan N, et al. Microglial-derived microparticles mediate neuroinflammation after traumatic brain injury. J Neuroinflammation (2017) 14(1):47. doi:10.1186/s12974017-0819-4

136. Harrison EB, Hochfelder CG, Lamberty BG, Meays BM, Morsey BM, Kelso ML, et al. Traumatic brain injury increases levels of miR-21 in extracellular vesicles: implications for neuroinflammation. FEBS Open Bio (2016) 6(8):835-46. doi:10.1002/2211-5463.12092

137. Klingeborn M, Dismuke WM, Bowes RC, Stamer WD. Roles of exosomes in the normal and diseased eye. Prog Retin Eye Res (2017) 59:158-77. doi:10.1016/j.preteyeres.2017.04.004

138. Anderson DH, Radeke MJ, Gallo NB, Chapin EA, Johnson PT, Curletti CR, et al. The pivotal role of the complement system in aging and age-related macular degeneration: hypothesis re-visited. Prog Retin Eye Res (2010) 29(2):95-112. doi:10.1016/j.preteyeres.2009.11.003

139. Han KY, Dugas-Ford J, Seiki M, Chang JH, Azar DT. Evidence for the involvement of MMP14 in MMP2 processing and recruitment in exosomes of corneal fibroblasts. Invest Ophthalmol Vis Sci (2015) 56(9):5323-9. doi:10.1167/iovs.14-14417

140. Budnik V, Ruiz-Canada C, Wendler F. Extracellular vesicles round off communication in the nervous system. Nat Rev Neurosci (2016) 17(3):160-72. doi:10.1038/nrn.2015.29

141. Scotter EL, Chen HJ, Shaw CE. TDP-43 proteinopathy and ALS: insights into disease mechanisms and therapeutic targets. Neurotherapeutics (2015) 12(2):352-63. doi:10.1007/s13311-015-0351-0

142. Mackenzie IR, Rademakers R. The role of transactive response DNA-binding protein-43 in amyotrophic lateral sclerosis and frontotemporal dementia. Curr Opin Neurol (2008) 21(6):693-700. doi:10.1097/WCO.0b013e3283168d1d

143. Feneberg E, Steinacker P, Lehnert S, Schneider A, Walther P, Thal DR, et al. Limited role of free TDP-43 as a diagnostic tool in neurodegenerative diseases. Amyotroph Lateral Scler Frontotemporal Degener (2014) 15(5-6):351-6. doi:10.3109/21678421.2014.905606

144. Thompson AG, Gray E, Heman-Ackah SM, Mager I, Talbot K, Andaloussi SE, et al. Extracellular vesicles in neurodegenerative disease - pathogenesis to biomarkers. Nat Rev Neurol (2016) 12(6):346-57. doi:10.1038/nrneurol. 2016.68

145. Vallhov H, Gutzeit C, Johansson SM, Nagy N, Paul M, Li Q, et al. Exosomes containing glycoprotein 350 released by EBV-transformed B cells selectively target B cells through CD21 and block EBV infection in vitro. J Immunol (2011) 186(1):73-82. doi:10.4049/jimmunol.1001145

146. Guo BB, Bellingham SA, Hill AF. Stimulating the release of exosomes increases the intercellular transfer of prions. J Biol Chem (2016) 291(10):5128-37. doi:10.1074/jbc.M115.684258

147. Jia S, Zocco D, Samuels ML, Chou MF, Chammas R, Skog J, et al. Emerging technologies in extracellular vesicle-based molecular diagnostics. Expert Rev Mol Diagn (2014) 14(3):307-21. doi:10.1586/14737159.2014.893828

148. Lener T, Gimona M, Aigner L, Borger V, Buzas E, Camussi G, et al. Applying extracellular vesicles based therapeutics in clinical trials - an ISEV position paper. J Extracell Vesicles (2015) 4:30087. doi:10.3402/jev.v4.30087

149. Fricke A, Ullrich PV, Cimniak AF, Follo M, Nestel S, Heimrich B, et al. Synovial sarcoma microvesicles harbor the SYT-SSX fusion gene transcript: comparison of different methods of detection and implications in biomarker research. Stem Cells Int (2016) 2016:6146047. doi:10.1155/2016/6146047

150. Ferrara $P$. The unbiased search of biomarkers in neurodegenerative diseases. Curr Pharm Biotechnol (2016) 17(5):471-9. doi:10.2174/138920101705160 303165719

151. Larssen P, Wik L, Czarnewski P, Eldh M, Lof L, Ronquist KG, et al. Tracing cellular origin of human exosomes using multiplex proximity extension assays. Mol Cell Proteomics (2017) 16(8):1547. doi:10.1074/mcp.M116.064725

152. Jayachandran M, Miller VM, Heit JA, Owen WG. Methodology for isolation, identification and characterization of microvesicles in peripheral blood. J Immunol Methods (2012) 375(1-2):207-14. doi:10.1016/j.jim.2011.10.012

153. Lamichhane TN, Sokic S, Schardt JS, Raiker RS, Lin JW, Jay SM. Emerging roles for extracellular vesicles in tissue engineering and regenerative medicine. Tissue Eng Part B Rev (2015) 21(1):45-54. doi:10.1089/ten.TEB.2014.0300

154. Ridder K, Keller S, Dams M, Rupp AK, Schlaudraff J, Del TD, et al. Extracellular vesicle-mediated transfer of genetic information between the hematopoietic system and the brain in response to inflammation. PLoS Biol (2014) 12(6):e1001874. doi:10.1371/journal.pbio.1001874

155. Nathanson D, Mischel PS. Charting the course across the blood-brain barrier. J Clin Invest (2011) 121(1):31-3. doi:10.1172/JCI45758

156. van den Boorn JG, Schlee M, Coch C, Hartmann G. SiRNA delivery with exosome nanoparticles. Nat Biotechnol (2011) 29(4):325-6. doi:10.1038/ nbt. 1830

157. Wang L, Li F, Dang L, Liang C, Wang C, He B, et al. In vivo delivery systems for therapeutic genome editing. Int J Mol Sci (2016) 17(5). doi:10.3390/ ijms 17050626

158. Morton LA, Saludes JP, Yin H. Constant pressure-controlled extrusion method for the preparation of nano-sized lipid vesicles. J Vis Exp (2012) (64):4151. doi:10.3791/4151

159. Noble S, Pasi J. Epidemiology and pathophysiology of cancer-associated thrombosis. BrJ Cancer (2010) 102(Suppl 1):S2-9. doi:10.1038/sj.bjc.6605599

160. Smyth T, Kullberg M, Malik N, Smith-Jones P, Graner MW, Anchordoquy TJ. Biodistribution and delivery efficiency of unmodified tumor-derived exosomes. J Control Release (2015) 199:145-55. doi:10.1016/j.jconrel.2014.12.013

161. Kooijmans SA, Vader P, van Dommelen SM, van Solinge WW, Schiffelers RM. Exosome mimetics: a novel class of drug delivery systems. Int J Nanomedicine (2012) 7:1525-41. doi:10.2147/IJN.S29661

162. Kooijmans SAA, Fliervoet LAL, van der Meel R, Fens MHAM, Heijnen HFG, van Bergen en Henegouwen PMP, et al. PEGylated and targeted extracellular vesicles display enhanced cell specificity and circulation time. J Control Release (2016) 224:77-85. doi:10.1016/j.jconrel.2016.01.009

163. Cui J, Li C, Wang C, Li Y, Zhang L, Zhang L, et al. Repeated injection of pegylated liposomal antitumour drugs induces the disappearance of the rapid distribution phase. J Pharm Pharmacol (2008) 60(12):1651-7. doi:10.1211/ jpp/60.12.0011

164. Xitong D, Xiaorong Z. Targeted therapeutic delivery using engineered exosomes and its applications in cardiovascular diseases. Gene (2016) 575 (2 Pt 2):377-84. doi:10.1016/j.gene.2015.08.067

165. Ohno S, Drummen GP, Kuroda M. Focus on extracellular vesicles: development of extracellular vesicle-based therapeutic systems. Int J Mol Sci (2016) 17(2):172. doi:10.3390/ijms17020172

166. Szebeni J. Complement activation-related pseudoallergy: a stress reaction in blood triggered by nanomedicines and biologicals. Mol Immunol (2014) 61(2):163-73. doi:10.1016/j.molimm.2014.06.038

167. Milosevits G, Szebeni J, Krol S. Exosomes: potential model for complementstealth delivery systems. Eur J Nanomed (2015) 7(3):207-2018. doi:10.1515/ ejnm-2015-0005 
168. Zhuang X, Xiang X, Grizzle W, Sun D, Zhang S, Axtell RC, et al. Treatment of brain inflammatory diseases by delivering exosome encapsulated anti-inflammatory drugs from the nasal region to the brain. Mol Ther (2011) 19(10):1769-79. doi:10.1038/mt.2011.164

169. Gao J, Wang S, Wang Z. High yield, scalable and remotely drug-loaded neutrophil-derived extracellular vesicles (EVs) for anti-inflammation therapy. Biomaterials (2017) 135:62-73. doi:10.1016/j.biomaterials.2017.05.003

170. Knickelbein JE, Liu B, Arakelyan A, Zicari S, Hannes S, Chen P, et al. Modulation of immune responses by extracellular vesicles from retinal pigment epithelium. Invest Ophthalmol Vis Sci (2016) 57(10):4101-7. doi:10.1167/iovs.15-18353
Conflict of Interest Statement: The authors declare that the research was conducted in the absence of any commercial or financial relationships that could be construed as a potential conflict of interest.

Copyright (c) 2018 Karasu, Eisenhardt, Harant and Huber-Lang. This is an open-access article distributed under the terms of the Creative Commons Attribution License (CC BY). The use, distribution or reproduction in other forums is permitted, provided the original author(s) and the copyright owner are credited and that the original publication in this journal is cited, in accordance with accepted academic practice. No use, distribution or reproduction is permitted which does not comply with these terms. 